\title{
Short-term effects of neodymium-YAG transscleral cyclocoagulation in patients with uncontrolled glaucoma
}

\author{
O BADEEB, G E TROPE, AND C MORTIMER
}

From the Department of Ophthalmology, Toronto General Hospital, University of Toronto, Toronto, Ontario, Candada

SUMMARY Transscleral Nd-YAG cyclocoagulation has been reported to lower intraocular pressure (IOP) in animals, eyes and more recently in human eyes. We treated 14 patients with uncontrolled IOP using this technique. Three patients were lost to follow-up. The mean follow-up time was 12 (SD 2.6) weeks. There was a decrease in IOP in all patients. Seven patients had final IOP readings $\leqslant 25 \mathrm{mmHg}(63 \cdot 6 \%)$. Six patients had IOP $\leqslant 21 \mathrm{mmHg}(54 \cdot 5 \%)$. Fairly severe complications occurred in most patients. None, however, developed phthisis bulbi. Two patients had one treatment $(18 \%)$, eight patients had two treatments $(72 \%)$, and one patient had three treatments $(9 \%)$. This preliminary study confirms that Nd-YAG cyclocoagulation effectively lowers IOP in patients with uncontrolled glaucoma over the short term.

Beckman et al. reported that trans-scleral ruby laser treatment of the ciliary body lowers IOP in both animals and human eyes by causing destruction of the ciliary body. ${ }^{12}$ In 1985 Wilensky et al. reported that trans-scleral Nd-YAG cyclocoagulation can be used to decrease IOP in rabbits. ${ }^{3}$ This effect has recently been confirmed by Devenyi $\mathrm{et} \mathrm{al.}{ }^{4}$

The purpose of this pilot study was to determine whether trans-scleral Nd-YAG cyclocoagulation can lower IOP in patients with uncontrolled glaucoma.

\section{Material and methods}

Prior to the start of this study a recently enucleated human cadaver eye was treated with Nd-YAG laser 2-3 $\mathrm{mm}$ from the limbus with energy levels as indicated below. This eye was then studied histopathologically to ensure that the laser was focused in the region of the ciliary processes.

Fourteen patients with uncontrolled IOP were treated with the trans-scleral Nd-YAG (thermal mode) cyclocoagulation as follows. All patients were admitted to hospital. All received a complete physical and ocular examination which included

Correspondence to Dr G E Trope, FRCS(C), Glaucoma Service, Toronto General Hospital, 200 Elizabeth Street, EN 5-308 Toronto, Ontario, Canada M5G 2C4. visual acuity, slit-lamp, Goldmann applanation tonometry, gonioscopy, and funduscopy. Informed consent was obtained from all patients.

Of the 14 patients treated 10 had neovascular glaucoma (NVG), three had secondary angle closure glaucoma (2nd ACG), and one had aniridia.

All patients were given retrobulbar anaesthesia with 3-4 ml xylocaine $2 \%$ bupivacaine $0.5 \%$ mixture 15 minutes before the treatment. A lid speculum and tooth forceps were used to keep the eye open and to move the eye so that the laser beam could be applied as perpendicular to the sclera as possible.

The Lasag Microruptor-2 neodymium-YAG laser

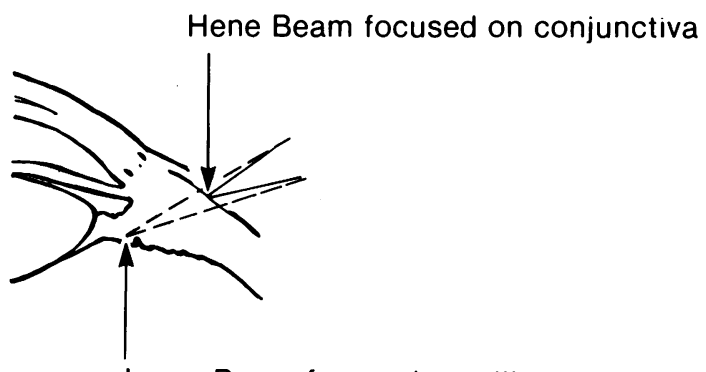

Laser Beam focused on ciliary processes

Fig. 1 Laser beam focused on the ciliary processes by offsetting the machine ' 9 '. 


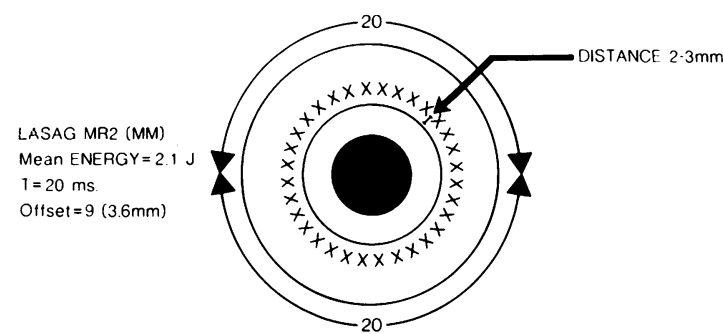

Fig. 2 Location and number of Nd-YAG laser burns in relation to the limbus.

set in the thermal mode was used. The mean energy was 2.10 joules $(1.98-2.25 \mathrm{~J})$ at $20 \mathrm{~ms}$. The Hene beam was focused on the conjunctival surface with the offset at ' 9 ' (Fig. 1). The mean number of laser

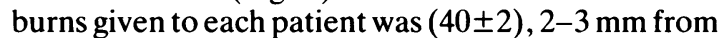
the limbus as measured with a caliper through $360^{\circ}$ (Fig. 2).

The patients' mean age was 58.7 years $(32-80$ years). Six patients were females and eight were males. Pretreatment visual acuity ranged from counting fingers at $1.5 \mathrm{~m}$ to no light perception.

Post-treatment therapy included Pred Forte (prednisolone) 3-4 hourly and atropine $1 \%$ twice daily. All pre-treatment antiglaucoma medications were continued. Pain medication was prescribed if required.

All patients had an ocular examination and IOP check 24 hours after treatment and were then discharged from the hospital. The follow-up protocol included weekly, monthly, three-monthly, and then six-monthly examinations.

If the IOP $\geqslant 30 \mathrm{mmHg}$ after one month the treatment was repeated up to three times. If the IOP did not drop to below $25 \mathrm{mmHg}$ after three treatments, this result was considered a treatment failure. Student's $t$ test was used to compare pre-laser with post-laser IOP levels.

\section{Results}

Three patients were lost to follow-up. Fig. 3 shows the IOP response to treatment. As indicated seven patients $(63.6 \%)$ had IOP $\leqslant 25 \mathrm{mmHg}$. Six patients $(54.5 \%)$ had an IOP drop $\leqslant 21 \mathrm{mmHg}$.

Fig. 4 shows the mean pre-laser and post-laser IOPs for the treated group as a whole. As indicated, there was a substantial drop in IOP from $48.5 \mathrm{mmHg}$ to $24.2 \mathrm{mmHg}$, which was statistically significant.

The success rate differed according to the type of glaucoma. It was $57 \%$ for NVG and $75 \%$ for the others.

Of the 11 patients studied, two received one treatment, eight received two treatments, and one

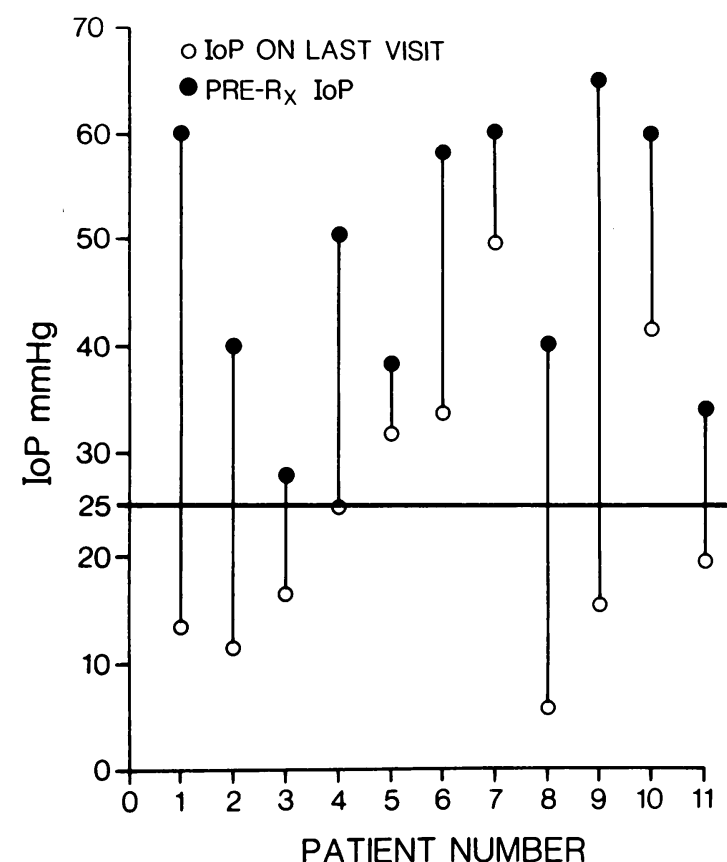

Fig. 3 IOP readings before and after Nd-YAG laser treatment. $R_{\mathrm{\chi}}=$ treatment.

had three treatments. The mean follow-up time was 12.0 (SD 2.6) weeks.

Post-treatment visual acuity remained the same in eight patients, improved in two patients, and deteriorated in one patient owing to development of a dense cataract.

Table 1 lists the complications seen in the eleven patients. As indicated, all patients developed corneal oedema, conjunctival injection, and iritis after treatment. Pain and gas bubbles in the anterior chamber were seen in five patients. Hypopyon developed in

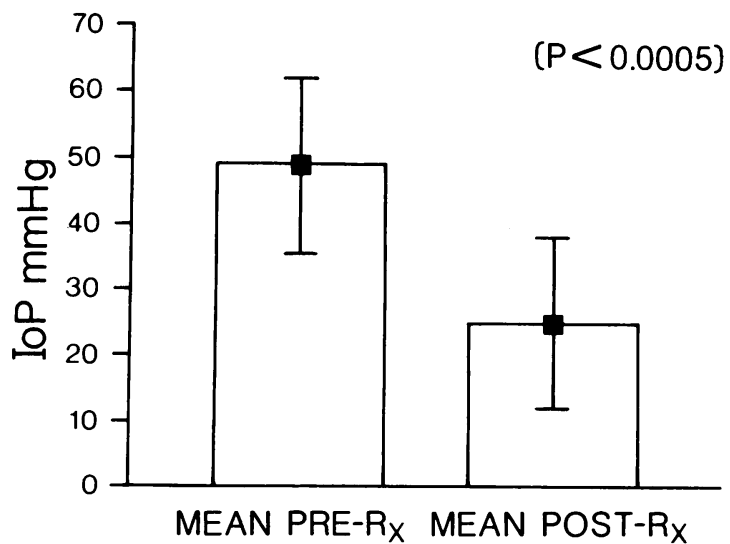

Fig. 4 Mean pre-and post-treatment IOP. $R_{\mathrm{x}}=$ treatment. 
Table 1 Complications in 11 patients

\begin{tabular}{ll}
\hline Complications & $\begin{array}{l}\text { No. of patients } \\
\text { affected }\end{array}$ \\
\hline Corneal oedema & 11 \\
Conj. injection & 11 \\
Iritis & 11 \\
Pain & 5 \\
Gas in anterior chamber & 5 \\
Hypopyon & 4 \\
Hyphaema & 3 \\
Cataract & 1 \\
Vitreous haemorrhage & 1 \\
Phthisis & 0 \\
\hline
\end{tabular}

four patients. Hyphaema developed in three patients. Cataract and vitreous haemorrhage developed in one patient. None of our patients developed phthisis bulbi over this time period.

\section{Discussion}

Uncontrolled glaucoma despite maximum medical therapy and failed filtration surgery remains a challenge to the surgeon. Many types of treatment are advocated, including cyclocryotherapy, ${ }^{5}$ modified trabeculectomy, ${ }^{6}$ seton implantation, ${ }^{7}$ trabeculectomy with 5-fluorouracil, ${ }^{8}$ and therapeutic ultrasound. ${ }^{9}$ No method has proved to be entirely successful.

The Nd-YAG laser emits infrared light (wavelength $1064 \mathrm{~nm}$ ). This has been shown to penetrate six times more deeply into tissues than argon laser before being absorbed. ${ }^{10}$ The Nd-YAG in its thermal mode produces relatively low power outputs $(100$ $200 \mathrm{~W})$ owing to the long duration of the pulse (10-20 $\mathrm{ms})$. During trans-scleral Nd-YAG cyclocoagulation the infrared energy penetrates the sclera, eventually being absorbed by the melanin in the ciliary processes' pigment epithelium. The light energy is converted to heat in this tissue, with damage of the ciliary processes. This results in decreased aqueous production, leading to a drop in IOP. Devenyi et al. recently reported that the sclera is not affected by this procedure. ${ }^{4}$

Our preliminary results show that trans-scleral NdYAG cyclocoagulation successfully decreases IOP in all patients with uncontrolled glaucoma. However, only $63.6 \%$ of patients had a drop in IOP to $25 \mathrm{mmHg}$ or less. This result is similar to Beckman and Waeltermann's results with the ruby laser."

Master $e t$ al. recently reported that $2 \cdot 0 \mathrm{~J} /$ pulse is an adequate energy level to lower the IOP in patients with uncontrolled glaucoma without producing phthisis bulbi. ${ }^{12}$ Our study confirms this. But larger numbers of patients and longer follow-up times are required before the ideal energy levels can be recommended.

Despite being treated with low energy levels all our patients developed complications. Many were mild, but one patient (with NVG) developed a vitreous haemorrhage and cataract. Whether this complication was due to the Nd-YAG laser or to the natural history of the disease is not clear.

In conclusion, trans-scleral Nd-YAG cyclocoagulation appears to be an effective method of lowering the IOP in patients with severe uncontrolled glaucoma. It is, however, associated with significant complications. Long-term effects of this form of treatment on both IOP and ocular structures are not yet known.

We thank Dr Milan Tytla for the statistical advice and the ophthalmology residents at Toronto General Hospital for their help. We also thank Drs Feldman, Dixon, Shea, Wiss, and Nolan for referring patients. We thank Mara Bajc for typing the manuscript.

\section{References}

1 Beckman H, Kinoshita A, Rota A, Sugar HS. Transscleral ruby laser irradiation of the ciliary body in the treatment of intractable glaucoma: Ophthalmology 1972; 76: 423-36.

2 Beckman H, Sugar HS. Neodymium laser cyclocoagulation. Arch Ophthalmol 1973; 90: 27-8.

3 Wilensky JT, Welch D, Mirolovich M. Transscleral cyclocoagulation using a neodymium-YAG laser. Ophthalmic Surg 1985; 16: $95-8$.

4 Devenyi R, Trope GE, Hunter W. Neodymium-YAG transscleral cyclocoagulation in rabbit eyes. BrJ Ophthalmol 1987: 71: 441-4.

5 Krupin T, Mitchell KB, Becker B. Cyclocryotherapy in neovascular glaucoma. Am J Ophthalmol 1978; 86: 24-6.

6 Herschler J, Agness D. A modified filtering operation for neovascular glaucoma. Arch Ophthalmol 1979; 97: 2339-41.

7 Sutton GE, Popp JC, Records RE. Krupin-Denver valve and neovascular glaucoma. Trans Ophthalmol Soc UK 1982; 102: 119-21.

8 Heuer D, Parrish II R, Gressel M, Hodapp E, Palmberg P, Anderson D. 5-Fluorouracil and glaucoma filtering surgery. II: A pilot study. Ophthalmology 1984; 91 : 384-94.

9 Coleman D, Lizzi F, Driller J, et al. Therapeutic ultrasound in the treatment of glaucoma. II: Clinical application. Ophthalmology 1985; 92: 347-53.

10 Van der Zypen E, Fankhauser F. Laser in the treatment of chronic simple glaucoma. Trans Ophthalmol Soc UK 1982; 102: $147-53$.

11 Beckman $\mathrm{H}$, Waeltermann J. Transscleral ruby laser cyclocoagulation. Am J Ophithalmol 1984; 98: 788-95.

12 Master MR, Schwartz LW, Cantor LB, Wilson RP, Spaeth GL. Treatment of advanced glaucoma with Nd-YAG laser cyclodiathermy. Invest Ophthalmol Vis Sci 1986; 27 (ARVO suppl): 253.

Accepted for publication 2 July 1987. 